\title{
Discussion and Summary
}

The present study confirms and extends the established observation that penicillin penetrates in adequate therapeutic levels into the interior of the eye if sufficiently massive doses are employed systemically. It is also shown that the local administration of penicillin, whether by retrobulbar or subconjunctival route, gives distinctly higher and more maintained intra-ocular levels than an injection of a corresponding dose intramuscularly. This applies to all ocular tissues and not only to the aqueous and vitreous. The effect of adrenalin in reaching and maintaining high intra.ocular levels is more marked with subconjunctival injections than with retrobulbar injections. When doses of $1,000,000$ units crystalline penicillin in adrenalin solution $1: 1,000$ are injected subconjunctivally, experiments in the rabbit suggest that an adequate level is reached and maintained in both vitreous and aqueous for -at least 48 hours. The high level reached and maintained in the vitreous by this dose and mode of administration is particularly noteworthy, for neither massive intramuscular injections nor injections of 50,000 units in adrenalin subconjunctivally give high or persistent levels of penicillin in the vitreous. This dose and mode of administration would appear to render superfluous any direct intravitreal injection of penicillin.

\section{REFERENCES}

Sorsby, A. and Ungar, J. (1946).-Brit. Med. Jl, Vol. II, p. 723. (1947).-Brit. Jl. Ophthal., Vol. XXI, p. 517.

Struble, B. C. and-Bellows, J. G. (1944).-Jl. Amer. Med. Assoc., Vol. CXXV, p. 685.

Town, A. E., FRISBE, E. F. C. and WISDA, J. G. (1946).-Amer. Jl. Ophthal., Vol. XXIX, p. 341 .

Town, A: E. and HunT, M. E. (1946).-Ibid., Vol. XXIX, p. 171.

\section{THE CONTROL OF EXPERIMENTAL INFECTIONS OF THE ANTERIOR CHAMBER AND OF THE VITREOUS BY SUBCONJUNCTIVAL AND RETROBULBAR INJECTIONS OF CRYSTALLINE PENICILLIN IN DOSES OF $1,000,000$ UNITS}

BY

\section{ARNOLD SORSBY and JOSEPH UNGAR}

LONDON

IT was shown in an earlier study (Sorsby and Ungar, 1946) that infection of the anterior chamber in the experimental animal could be controlled readily by subconjunctival injections of 25,000 units 
penicillin; the application of concentrated ointment, or intramuscular injection of penicillin gave less ready control. Vitreous infections did not respond too well to intramuscular injections, still less to ointment, and whilst subconjunctival injections gave satisfactory results, these were not uniform. The response of vitreous infection to direct intravitreal injection of penicillin was also not too satisfactory (Sorsby and Ungar, 1948). In the present study the effect of doses of $1,000,000$ units of crystalline penicillin injected subconjunctivally or retrobulbarly have been investigated in order to determine whether more consistent results could be obtained, and whether the frequency of injection could be reduced. Infection was induced by introducing into the anterior chamber or into the vitreous a suspension of 50,000 staphylococcus aureus organisms in $0.05 \mathrm{ml}$. of saline.

\section{1.-Infection of the anterior chamber}

\section{Treatment by subconjunctival injection.}

Seven adult rabbits were used, of which two were controls. Both control rabbits showed a destructive panophthalmitis within 48 hours. Of the remaining 5,3 received the first treatment four hours after the infection and two 24 hours after the infection.

(a) Three rabbits first treated four hours after infection.-These animals received a subconjunctival injection of $1,000,000$ units penicillin in $1 \mathrm{ml}$. water 4 hours after infection, the dose being repeated 20 hours later. The animals therefore received in all two injections. These three rabbits showed slight conjunctival oedema 48 hours after infection, but their corneae were clear. They made an uninterrupted recovery and they were destroyed 12 days after infection, when their eyes were completely normal.

(b) Two rabbits first treated 24 hours after infection.-In addition to the initial injection of $1,000,000$ units 24 hours after infection a further subconjunctival injection of $1,000,000$ units was given at 48 hours and at 72 hours after infection. There was considerable cloudiness of the cornea and congestion of the iris when treatment was first instituted and these signs tended to clear progressively. At the end of 10 days the eye of one rabbit was practically normal, and that of the other showed local corneal infiltration with the anterior chamber still somewhat hazy. At 14 days the first of these rabbits still showed blepharospasm and some injection of the conjunctiva, whilst the second now had a definite corneal ulcer with much conjunctival injection and blepharospasm. By 21 days both eyes were relatively normal. In the first rabbit there was a small posterior synechia at 6 o'clock, and in the second there was a small corneal scar. 
2. Treatment by deep orbital injection.

Four adult rabbits were used and one control. Two rabbits were first treated 4 hours after infection and 2 more 24 hours after infection. The control rabbit showed marked engorgement of the globe within 24 hours and extensive disorganization of the eye after three days.

(a) Two rabbits first treated 4 hours after infection. - These animals received $1,000,000$ units of penicillin in $1 \mathrm{ml}$. of water 4 hours after infection, and another injection at 24 hours. Of these two, one was completely normal within 24 hours and remained so; the second showed a persistent corneal haze and was destroyed on the 17th day, when the lower part of the cornea was diffusely opaque. A good red reflex was present ophthalmoscopically.

(b) Two rabbits first treated 24 ,hours after infection. - A good functional result was obtained in one, the cornea showing little more than a localised scar near the site of the inoculation. The second animal showed extensive corneal haze with considerable iritis.

Judging by the results in this small series, the time at which treatment is initiated is a determining factor for a rapid and uneventful recovery, and subconjunctival injection is probably the better procedure.

\section{- 2.-Infections of the vitreous}

\section{Treatment by subconjunctival injection.}

Five adult rabbits were used, one as the control; two were first treated 4 hours after infection, and two at 24 hours after infection. The control animal showed a grey vitreous reflex within 24 hours.

(a) Two rabbits first treated 4 hours after infection. - These animals received a subconjunctival injection of 1,000,000 units of penicillin in $1 \mathrm{ml}$. of water, the dose being repeated 20 hours later. After 24 hours both these rabbits showed externally normal eyes. At 72 hours the corneae were bright and there was a good red reflex ophthalmoscopically in both animals, but some vitreous haze was also present. Forty-eight hours later both these animals were found dead. Post-mortem examination revealed no definite abnormality systemically, and the bisected eyes appeared normal.

(b) Two rabbits first treated 24 hours after infection.- The first subconjunctival injection of $1,000,000$ units penicillin was followed by one more at 48 hours and another at 72 hours. There was considerable congestion of the globe at 20 hours in both animals, and at 48 hours a yellow reflex from the vitreous was present in both animals. At 72 hours the vitreous of one rabbit was an organized grey mass, and of the other an organized yellow mass 
with an associated iritis. The subsequent course was a grey reflex from the vitreous in a quiet eye with corneal haze in one animal, and panophthalmitis in the other.

2. Treatment by retrobulbar injection.

A series of 8 adult rabbits were used. Three rabbits were used as controls : within 48 hours they showed fairly well established panophthalmitis. When destroyed on the twelfth day their eyes were functionally useless; the corneae were hazy, vascularised and there was much bulbar injection. Of the remaining 5 rabbits three were first treated 4 hours after infection, and in two rabbits the first treatment was 24 hours after infection.

(a) Three rabbits first treated 4 hours after infection.-One of these received a second retrobulbar injection 24 hours after infection; the two other rabbits had only the first retrobulbar injection followed by four doses of 250,000 units intramuscularly on the second and third day. The first of these rabbits showed an uninterrupted recovery. Of the remaining two, one died on the fourth day after the ocular infection was running a favourable course. The second showed nothing more than a slight iritis with a mild hypopyon on the second day, and by the 12 th day the eye had become normal.

(b) Two rabbits first treated 24 hours after infection.-The first retrobulbar injection of 1,000,000 units of penicillin was followed by one more at 48 and another at $\dot{7} 2$ hours. By the time treatment was begun there was considerable cloudiness of the cornea, and anterior chamber. On the 10 th day both these animals showed a distinct yellow reflex from the vitreous. On the 14 th day one showed a corneal ulcer with considerable corneal haze obscuring a view of the interior. In the second animal the cornea and anterior chamber were clear, but the vitreous gave a grey reflex. At 21 days the first animal showed a total vascularised opacification of the cornea; the second with a clear cornea showed a completely organized vitreous.

In infection of the vitreous, as in that of the anterior chamber, the time that the treatment was begun would therefore appear to be one of the determining factors in obtaining a satisfactory response. The available data do not allow a comparative assessment as between subconjunctival and retrobulbar injection.

\section{Discussion}

The present study confirms the earlier findings that infections of the anterior chamber can be readily controlled by subconjunctival injections of penicillin in adequate doses. From the study previously published it appeared that with doses of the order of 
20,000 units of penicillin injections at intervals of about 6 hours were necessary. The present study suggests that when the infection is not fully established two or three subconjunctival or possibly retrobulbar injections of $1,000,000$ units at intervals of 24 hours should control a fairly severe infection of the anterior chamber.

Vitreous infections, which do not give such satisfactory results as infections of the anterior chamber on treatment by subconjunctival injections of relatively small doses of penicillin (of the order of 20,000 units), and do not respond too well to direct intravitreal injection of penicillin, appear to respond to two injections of $1,000,000$ units at intervals of 20 hours if treatment is begun sufficiently early. With the dose of infection used in these experiments the results were disappointing if treatment was begun after 24 hours : the results were satisfactory if treatment was begun within 4 hours.

\section{Summary}

(1) Experimental infections were induced in the rabbit by injecting into the anterior chamber, or into the vitreous, a suspension of 50,000 staphylococcus aureus organisms in $0.05 \mathrm{ml}$. saline.

(2) In 9 rabbits the anterior chamber was infected, of these 5 were treated by subconjunctival injection, three receiving their first treatment 4 hours after infection and two 24 hours after infection. Four rabbits were treated by retrobulbar injection, 2 receiving the first treatment 4 hours after infection, and two 24 hours after infection. The three rabbits treated by subconjunctival injection 4 hours after infection made an uninterrupted recovery; the 2 rabbits first treated 24 hours after infection also did well, but the course of the infection was more prolonged, and the sequelae were rather more marked. Of the two rabbits treated 4 hours after infection by retrobulbar injection one made a complete recovery; in the two treated 24 hours after infection, recovery was not so good.

The mode of treatment was $1,000,000$ units of crystalline penicillin in $1 \mathrm{ml}$. of water subconjunctivally or retrobulbarly at each injection. The rabbits treated four hours after infection received a second dose 20 hours later. The rabbits treated 24 hours after infection received subsequent doses at 48 and 72 hours.

The control animals did uniformly badly.

(3) Nine rabbits had intravitreal infection. Four were treated by subconjunctivat injection and 5 by retrobulbar injection. The doses and time intervals were essentially similar to those employed for anterior chamber infections. The control rabbits did uniformly badly. The two rabbits first treated by subconjunctival injections 4 hours after infection did well. In contrast, the two rabbits first 
treated 24 hours after infection showed disorganized globes. Three rabbits first treated 4 hours after infection by retrobulbar injection also did well, whilst 2 rabbits first treated 24 hours after infection did badly.

We are indebted to $\mathrm{Mr}$. B. Helliwell of the Research Division, Glaxo Laboratories for technical help in the studies recorded in this and the two preceding papers.

\title{
REFERENCES
}

SorsBy, A. and Ungar, J. (1946).-Brit. Med. Jl., ii, p. 723.

(1948).-Brit. Ji. Ophthal. This issue, p. 857.

\section{PRELIMINARY NOTE ON THE TREATMENT OF HYPOPYON ULCER BY CRYSTALLINE PENICILLIN IN ADRENALIN IN DOSES IN EXCESS OF 50,000 UNITS INJECTED BY SUBCONJUNCTIVAL OR RETROBULBAR ROUTES}

\author{
BY \\ ARNOLD SORSBY and JOSEPH UNGAR \\ LONDON
}

WhILST the experimental results recorded in the two preceding studies were being. established, a parallel investigation was conducted clinically to establish whether the eye tolerates subconjunctival injections of more than 50,000 units of crystalline penicillin and whether the frequency of application could be reduced. The experimental results suggested that higher doses than 50,000 units have the two-fold advantage of giving a higher concentration of penicillin intra-ocularly and that thisconcentration persisted for longer than with the smaller doses. In an earlier study (Sorsby and Reed, 194ז) dosage of 50,000 units of crystalline penicillin in adrenalin at six hourly intervals was advocated. The new experimental data suggested that with injections of $1,000,000$ units in adrenalin the intervals might be prolonged to 48 hours.

The following brief notes are recorded to show that at this stage 6 hourly injections of 50,000 units of crystalline penicillin can safely and with advantage be replaced by doses of 500,000 units of crystalline penicillin in adrenalin at intervals of 24 hours.

(1) Two cases treated by injection of 100,000 units in $0.5 \mathrm{ml}$. at 12 hourly intervals.

(a) A man, aged 37 years, with an infected corneal ulcer and a minimal hypopyon, showed no intolerance to subconjunctival 